\title{
Survival, Virulence Gene Expression and Difference in the Drug Susceptibility of Non-typhoidal Salmonella in Gut Physiological Conditions
}

\author{
Akshatha Kotian \\ Nitte University Centre for Science Education and Research \\ Vankadari Aditya \\ Nitte University Centre for Science Education and Research \\ Jassiya Sheikh \\ Nitte University Centre for Science Education and Research \\ Sreya Saikrishnan \\ Nitte University Centre for Science Education and Research \\ Praveen Rai \\ Nitte University Centre for Science Education and Research \\ Anirban Chakraborty \\ Nitte University Centre for Science Education and Research \\ Indrani Karunasagar \\ Nitte University Centre for Science Education and Research \\ VK Deekshit ( $\square$ deekshit1486@nitte.edu.in ) \\ Nitte University Centre for Science Education and Research Nitte (Deemed to be University) \\ https://orcid.org/0000-0002-3535-5528
}

\section{Research Article}

Keywords: Non- typhoidal Salmonella, antibiotic resistance, growth kinetics, in vitro gut conditions, multi drug resistant

Posted Date: May 25th, 2021

DOI: https://doi.org/10.21203/rs.3.rs-479102/v1

License: (c) (i) This work is licensed under a Creative Commons Attribution 4.0 International License.

Read Full License 


\section{Abstract}

Salmonella is one among the most versatile and resilient enteric pathogens that known to have developed various survival strategies within the host system. The ability of the bacteria to circumvent the physiological parameters as well as dodge the antimicrobial stress environment within the host is one of the most crucial steps in establishing an infection. With an alarming rise in multi-drug resistant serovars of non-typhoidal Salmonella and lack of vaccine for combatting the infections, behaviour of the bacteria in the presence of host physiological gut conditions ( $\mathrm{NaCl}$, high and low iron) and antibiotics will help in understanding the survival strategies as well as mechanisms of resistance. 59 non-typhoidal Salmonella serovars isolated from poultry and seafood were used in the study. The isolates were screened for their antibiotic susceptibility patterns. Two multi-drug resistant and two sensitive serovars were used for growth kinetics and virulence gene expression study. The results obtained revealed that despite similar resistance pattern, the effect of individual class of antibiotics on the growth of serovars varied. On contrary, no significant difference was observed in growth pattern on exposure to in vitro gut like experimental conditions. Nevertheless, the in-vitro gut conditions and exposure to antibiotics have drastically reduced the minimum inhibitory concentration of antibiotics in resistant strains. A first of its kind study that draws attention on the significant effect of antibiotics and gut physiological conditions on MIC and expression of virulence genes from Salmonella pathogenicity island (SPI) 1 and 2 between resistant and sensitive non typhoidal Salmonella serovars.

\section{Introduction}

Ever since the discovery of the first antibiotic in 1928, countless lives have been saved from dreaded bacterial infections worldwide. However, their indiscriminate use has led to the emergence of resistance among bacteria, particularly in common pathogens such as E. coli, Salmonella, Listeria, Klebseilla etc. With the inexorable rise in the use of antibiotics, their effectiveness in controlling bacterial infections has reduced drastically. Salmonella continues to remain a major public health concern worldwide (Majowicz et al. 2010). According to a recent data from Centre of Disease Control, USA, non-typhoidal Salmonella accounts for about 1.2 million cases of gastrointestinal disease and approximately 500 deaths in the United States every year. Globally, the statistics is even more staggering, with 153 million cases of gastroenteritis and about 57,000 deaths each year (CDC yellow book 2020). Besides the early antibiotics, Salmonella is now resistant to several newer classes of drugs of the family ß-lactams, fluoroquinolones, aminoglycosides and colistin (Chen et al. 2013). Till date conventional methods like broth dilutions and disk diffusion tests are the most reliable and relevant method of susceptibility pattern (Jorgensen and Ferraro 2009). However these methods give end-point results after certain hours of incubation but do not assess the growth kinetics of the bacteria continuously to check the effect of antibiotics. Understanding the growth kinetics of individual bacteria under the antibiotic condition and how it contributes to its fitness in varying environmental conditions can help in cutting down the irrational use of antibiotics. In addition, the availability of nutrients within the host cell is an important factor for the efficient colonisation and expression of virulence characteristics in Salmonella (Spector and Kenyon 2012). 
Salmonella has undergone various adaptive changes to withstand stress conditions of the gut which are the integral part of the host defence system, including $\mathrm{pH}$, temperature, salt, bile salts, iron availability as well as compete with the hosts microbiome (Gonzales-Siles and Sjöling 2016; Yoon et al. 2013; Dichtl et al. 2019; Gunasekera et al. 2008). With the steady increase in the incidence of MDR nontyphoidal Salmonella outbreaks and the ability of the bacteria to survive in varied physiological condition within host, it is important to elucidate the behaviour of individual bacteria to correlate between host physiology, bacterial resistance, survival as well as virulence pattern.

\section{Materials And Methods Bacterial strains}

Non-typhoidal Salmonella serovars isolated from poultry and seafood were used in the study. Salmonella cultures were routinely revived and maintained in Luria-Bertani (LB) broth (HiMedia Laboratories Pvt. Ltd, India) and were incubated at $37^{\circ} \mathrm{C}$ overnight with shaking. For condition-based assays cultures were grown in LB broth supplemented with 0.3M NaCl (Sigma-Aldrich), $100 \mu \mathrm{M}$ Ferric chloride $\left(\mathrm{FeCl}_{3}\right)$ (Himedia Laboratories Pvt. Ltd., India) and 0.2mM 2,2-dipyridyl (Sigma-Aldrich).

\section{Antibiotic susceptibility test}

Antibiogram of 59 non- typhoidal Salmonella serovars, isolated from seafood, were studied by Kirby Bauer disc diffusion method according to CLSI guidelines (CLSI 2018) for a panel of 10 antibiotics viz nalidixic acid $(30 \mu \mathrm{g})$, ciprofloxacin $(5 \mu \mathrm{g})$, tetracycline $(30 \mu \mathrm{g})$, trimethoprim/sulfamethoxazole $(25 \mu \mathrm{g})$, piperacillin/tazobactum $(100 / 10 \mu \mathrm{g})$, imipenem $(10 \mu \mathrm{g})$, chloramphenicol $(30 \mu \mathrm{g})$, ampicillin $(10 \mu \mathrm{g})$, cefotaxime $(30 \mu \mathrm{g})$. ATCC $25922 \mathrm{E}$. coli was used as a quality control strain.

Two isolates showing multidrug resistance characteristic (SW9 and SN36)* and two sensitive isolates (SW65 and SN72) were selected for growth kinetic studies.

*Salmonella Welteverden and Salmonella Newport

\section{Growth kinetic study}

\section{Effect of antibiotics on the growth of resistant isolates}

The concentration of antibiotic solution used was based on the CLSI (2018) (Clinical Laboratory Standards Institute) breakpoints to be categorized as resistant. The solutions were added to the broth prior to the inoculation of the culture. An aliquot of the overnight culture was centrifuged. The cell pellets were washed twice with 1X PBS and resuspended in Luria Bertani (LB) broth and was used as inoculum. The culture flasks were incubated at $37^{\circ} \mathrm{C}$ with shaking at $200 \mathrm{rpm}$ in a shaker incubator (New Brunswick, 
Eppendorf) and the optical density at $600 \mathrm{~nm}\left(\mathrm{OD}_{600}\right)$ was determined every 2 hours for upto 30 hours. The experiments were performed in triplicates.

\section{Effect of $\mathrm{NaCl}$, high iron and low iron on the growth of MDR and drug sensitive isolates}

In order to see the effect of $\mathrm{NaCl}$, high iron and low iron on the growth of MDR serovars SW9 and SN36 as well as two drug sensitive serovars SW65 and SN7, the serovars were grown in LB broth supplemented with $0.3 \mathrm{M} \mathrm{NaCl}$ (salt condition), $100 \mathrm{Mm}$ of $\mathrm{FeCl}_{3}$ (high iron condition) and $0.2 \mathrm{Mm}$ of 2,2-dipyridyl (low iron condition). Growth kinetic experiments were performed in triplicates for $30 \mathrm{hrs}$ as mention earlier.

\section{MIC variation on exposure to physiological condition and antibiotic shocks}

Variation in MIC was determined for the resistant strains to see the effect of physiological condition as well as antibiotic shock using Ezy MIC ${ }^{\mathrm{TM}}$ strips (HiMedia Laboratories Pvt. Ltd., India). SW9 and SN36 were grown to mid-exponential phase (MEP) in LB broth supplemented with $0.3 \mathrm{M} \mathrm{NaCl}$ (salt condition), $100 \mathrm{Mm}$ of $\mathrm{FeCl}_{3}$ (high iron condition) and $0.2 \mathrm{Mm}$ of 2,2-dipyridyl (low iron condition). The culture was swabbed onto Muller Hinton agar plates and the MIC strips were placed on the plate using the provided applicator. The plates were incubated at $37 \mathrm{C}$ for $16-18 \mathrm{hrs}$. MIC was read where the ellipse intersects the MIC scale on the strip for 5 different antibiotics viz ampicillin, nalidixic acid, chloramphenicol, tetracycline, co-trimoxazole. Bacteria grown to MEP under different physiological condition was also subjected to a $30 \mathrm{~min}$ antibiotic shock individually and MIC variation was noted as discussed earlier.

\section{Differential gene expression study}

Expression of virulence genes were quantified for both the MDR and drug sensitive serovars using real time PCR under $\mathrm{NaCl}$, high iron and low iron conditions. The two MDR isolates were subjected to antibiotic challenge under each in vitro conditions for a brief period of $30 \mathrm{~min}$ and the virulence gene expression was quantified.

Bacterial cells were rapidly collected under each experimental condition. RNA extraction was done using the TRIzol method. Extracted RNA was subjected to DNase treatment as per manufactures protocol (Thermo Fisher Scientific Inc, USA). Absence of genomic DNA was confirmed using PCR. The amount of RNA was quantified using Biospectrophotometer and normalized followed by cDNA synthesis (TaKaRa PrimeScriptTM First Strand cDNA synthesis kit). The synthesized cDNA was used as a template for real time PCR. 
Real time PCR was used to quantify the level of expression of virulence genes from SPI-1 and SPI-2 that includes invasion genes (invA, hilC), motility gene (flic2), effector gene (sseA) and a regulatory gene $(s s r B)$ (Table 1). An appropriate housekeeping gene icdA was used as an internal standard. The quantitative real time PCR (qPCR) assay was performed using SsoAdvanced ${ }^{\text {TM }}$ universal SYBR green supermix (BioRad, USA). Melt curve analysis was performed for all the genes to rule out the amplification of untargeted fragments. mRNA transcripts were quantified using the $2^{-\Delta \Delta c t}$ formula (Livak and Schmittgen 2001). The qPCR was carried out in $10 \mu \mathrm{L}$ reaction volume consisting $5 \mu \mathrm{L}$ of SYBR green super mix, $0.8 \mu \mathrm{L}$ of $2.5 \mu \mathrm{M}$ of forward and reverse primers $(200 \mathrm{nM}), 1 \mu \mathrm{L}$ of template RNA and molecular grade water to adjust the volume. The plates were sealed and centrifuged at $2000 \mathrm{rpm}$ for $5 \mathrm{~min}$. The reaction was performed in real time PCR detection system (CFX96 Touch $^{\text {TM }}$, BioRad, USA). Data acquisition was performed by BioRad CFX Manager.

\section{Results}

\section{Antibogram analysis and antibiotic resistance determinants}

Thirty out of the fifty nine isolates used in the study were multi-drug resistant (MDR). 18 isolates were drug sensitive and the rest 11 isolates were resistant to only one antibiotic used in the study. Maximum sensitivity was seen towards chloramphenicol and ciprofloxacin $(91.37 \%)$ and maximum resistance was observed against nalidixic acid (50\%) followed by co-trimoxazole (44.8 3\%) as discussed in our previous study (Kotian et al. 2020). Two isolates, Salmonella Weltevreden (SW9) and Salmonella Newport (SN36) that showed resistance to 4 (nalidixic acid, tetracycline, chloramphenicol and co-trimoxazole) and 5 (nalidixic acid, tetracycline, chloramphenicol, ampicillin and co-trimoxazole) different classes of drugs respectively were chosen for further study.

Our earlier studies on the characterization of antibiotic resistance determinants by PCR revealed the presence of tetB and tetG genes in SW9 and SN36 respectively, confirming the phenotypic presentation of tetracycline resistance. SW9 showed resistance to chloramphenicol and was positive for catA1 while SN36, resistant to chloramphenicol, harboured floR (Deekshit et al. 2012). Both the resistant isolates were positive for sul 1 in accordance with the phenotypic resistance observed towards co-trimoxazole (trimethoprim/sulfamethoxazole). The data obtained in previous study showed the resistance to nalidixic acid in SW9 and SN36 was due to mutation in the QRDR region, with a single gyrA mutation at codon 83 (Ser to Tyr) in SW9 and a mutation at codon 87 (Asp to Asn) in SN36 (Deekshit et al. 2015).

\section{Variations in growth rates between the serovars in the presence of antibiotics}

Results of growth kinetics in the presence of antibiotics for the SW9 and SN36 revealed, slower growth with a longer lag phase in the presence of antibiotics as compared to the control condition (LB broth devoid of antibiotics). In the case of SW9, the growth rate was slower in the presence of co-trimoxazole 
when compared to tetracycline, chloramphenicol and nalidixic acid. Likewise, the presence of tetracycline resulted in an extended lag phase and higher effect when compared to the other antibiotics in SN36 (Figure 1).

\section{Effect of $\mathrm{NaCl}$, high iron and low iron condition on growth of drug resistant and sensitive serovars}

There was no significant difference in the growth pattern of sensitive and resistant serovars in the control conditions (LB broth). On exposure to experimental condition, no statistically significant difference was observed in the growth pattern. However, SN72 and SW9 on addition of ferric chloride showed a slight enhanced growth when compared to the control condition. In resistant isolate SN36, the culture density coincided on reaching the stationary phase in case of control as well as all the treated conditions, thereby, showing no effect of the condition provided. A slight difference in the culture density in the exponential phase was observed between the growth pattern of sensitive and resistant isolates on exposure to $0.3 \mathrm{M}$ $\mathrm{NaCl}$. No potential advantage in the growth was specifically observed as an effect of high iron or low iron between the resistant and sensitive serovars (Figure 2).

\section{Variation in MIC on exposure to gut physiological condition and antibiotic challenge}

Decrease in MIC in both the resistant isolates SW9 and SN36 was observed after exposure to physiological condition. In all the experimental conditions and in the presence of a particular antibiotic shock there was a decrease in the MIC value there by showing an increased susceptibly to the antibiotics to which the isolates were resistant (Table $2 a$ and $2 b$ ).

\section{Expression of virulence genes}

Differential expression of genes associated with motility (flic2) and invasion (invA and hilC), an effector gene essential for SPI2-mediated translocation of effector proteins ( $s S e A$ ) and a regulator gene from SPI$2(s s r B)$ were checked during the experimental condition. Under low iron conditions, an upregulation in invasion genes, invA and hilC as well as motility gene (flic2) was observed in both resistant and sensitive isolates. However, a decrease in expression of flic2 was seen in both the sensitive isolates (SN72 and SW65) on exposure to $0.3 \mathrm{M} \mathrm{NaCl}$. The transcriptional expression followed a trend for $s s r B$ and $s s e A$ genes wherein, an upregulation of the genes was observed in resistant isolates in all the three experimental conditions while it showed down regulation in the sensitive isolates (Figure 3).

On exposure to antibiotic challenge, motility gene (flic2) showed lesser expression compared to its expression obtained on exposure to infection based physiological conditions (Figure 4) Thus, the 
virulence gene expression showed variation among the resistant and sensitive isolates as well as the exposed environmental condition.

\section{Discussion}

Pathogenic bacteria must survive hostile environments within the host during the course of infection. Salmonella, being an enteric pathogen has developed various exquisite strategies to overcome this host physiological condition as well as the antibiotic stress. (Fang et al. 2014). The results of this study highlight that despite similar resistance pattern, the effect of individual class of antibiotics on the growth of the serovars varied. For instance, there was a significant difference $(p<0.001)$ between the growth observed in Salmonella Weltevreden (SW9) and Salmonella Newport (SN36) on exposure to tetracycline, most likely due to the presence of different efflux mediated tetracycline resistance genes namely tetB in SW9 and tetG in SN36. This further adds to the notion that efflux mediated resistance does affect bacterial fitness in the environment in which they live (Hong et al. 2014). Similarly, the differential growth curve in the presence of chloramphenicol observed in the MDR serovars could be possibly due to the presence of catA1 in SW9 and floR in SN36, which code for chloramphenicol acetyl transferase and some specific exporter proteins respectively (Schwarz et al. 2004). Interestingly, the growth rates varied in the presence of different antibiotics in different serovars which is in alignment with the concept of antibioticspecific dynamic changes (Theophel et al. 2014). There is a severe impact of antimicrobial drug dose exposure on microorganisms. However, further studies on the regulatory mechanisms of the resistance genes would help understand this differential growth pattern. Since, Salmonella is a food borne pathogen it is important to transit and possess strategies to survive various lethal stress conditions within host environment (Winfield and Groisman 2003). Response to the environmental stress alters the virulence gene expression and increases the pathogenic nature of the bacterium (Clements et al. 2001). We investigated the variation in expression of 5 virulence genes from Salmonella pathogenicity island (SPI) 1 and 2 (invA, flic2, hilC, ssrB and sseA) between resistant and sensitive serovars. Though prior studies proved high iron availability increased the growth and virulence potential of Salmonella Typhimurium (Kortman et al. 2012), in our study only SN72 and SW9 on addition of ferric chloride showed a slight enhanced growth when compared to the control condition. This could probably be a serovar specific adaptation to survive the environment condition. A slight difference in the culture density in the exponential phase was observed on exposure to $\mathrm{NaCl}$. The rapid adaptability to changes in osmotic pressure by Salmonella in host body can be attributed to the ability of the bacteria to survive in various host and non-host environments (Foster 1995). Although the study evaluated expression of limited genes it is worth noting that resistant and sensitive serovars showed a difference in expression trend in varying experimental condition. This variability observed may contribute to difference in virulence potential of the serovars. Gastrointestinal tract acts as a reservoir for the transfer of antibiotic resistance genes or in other words in leads to the increase in the number of resistant isolates. The ability to survive and replicate within the various harsh physiological parameters in host body as well as the ability to survive in antibiotic challenged environment possess a potential threat. The broad implication of the present research is that selective pressure from antibiotics and the surrounding host environment may induce 
variation in growth pattern and altered expression of virulence and antibiotic resistance genes. An alteration in the expression of gene on exposure to antibiotics was also noted in the study. A study by Brian et al 2015 showed that tetracycline and chloramphenicol decreased the motility and increased the invasion and attachment gene expression which is in agreement with the results obtained in this study, wherein a reduced expression of flic2 was observed on exposure to tetracycline and co-trimoxazole (Brunelle et al. 2014). Further, it is clear that increased virulence gene expression is observed on exposure of the bacteria to antibiotics in the presence of in vitro conditions. This could be a survival strategy adopted by the bacteria to overcome the host physiological conditions and this increased virulence pattern could be a potential threat in case of MDR strains as they can overcome the effect of antibiotics and thrive. Furthermore, decreased in MIC of antibiotics such as ampicillin, tetracycline, Chloramphenicol, cotrimoxazole and nalidixic acid was highly evident in drug resistant isolates SN36 and SW9 on exposure to gut physiological conditions and antibiotic challenge. This suggests that, though routine antimicrobial susceptibility testing reveal the resistance nature of the bacteria, it is important to understand the behaviour of these drug resistant pathogens under in-vitro gut conditions. This is the first of its kind study, wherein we showed in-vitro gut physiological condition such as $\mathrm{NaCl}$, high iron, low iron and antibiotic exposure reduced the MIC of nontyphoidal Salmonella serovars $S$. Newport (SN36) and $S$. Weltevreden (SW9) thereby making them susceptible to antibiotics to which otherwise they showed resistance.

\section{Conclusion}

Approaching antibiotic resistance as a single aetiology limits the logical approach of attaining new therapeutic strategy. Studying the behaviour of the bacteria in host physiological conditions as well as uncovering genetic interactions between virulence and resistance will help in bringing about a critical link in combatting MDR infections. Although preliminary, the results obtained points out that the heterogeneity between serovars must be taken into account in deciding an antibiotic treatment regime or while opting for the next generation of drugs. It can help rule out misinterpretation of susceptibility in bacteria and serve as a check point for emergence of resistant isolates. Understanding the variations in growth pattern of the bacteria on exposure to the antibiotics to which it is resistant to, as well as to host environment conditions could provide vital clues towards developing novel target specific therapeutics. The most important aspect of this study was the observation that despite being resistant to the same class of antibiotics, serovars show variation in the growth pattern, which could influence their virulence potential. Further, the reduction in MIC for antibiotics in resistant isolates upon antibiotic exposure and in the presence of gut physiological condition could be an important evidence to show that resistance microorganism might behave different in-vivo and become susceptible. In addition, the virulence gene expression pattern obtained varied between the resistant and sensitive isolate which shows the need to unravel the regulatory mechanisms correlating the environmental cues the bacteria encounters. Further work is certainly required to disentangle these complexities for better therapeutic strategies.

\section{Declarations}




\section{Acknowledgements:}

The authors are thankful to Nitte University Centre for Science Education and Research for providing the necessary facilities and research fellowships.

\section{Financial \& competing interests disclosure:}

Financial support received from the Government of India funded DST-SERB (Grant no. ECR/2017/000559) toward this study is gratefully acknowledged.

\section{Conflict of Interest :}

There is no conflict of interest among the authors.

\section{Research involving human and animal participants:}

This article does not contain any studies with human participants or animals.

\section{Consent for publications :}

All co-authors have agreed to the content and form of the manuscript for publication

\section{Ethical Approval :}

Not Applicable

\section{Author contributions:}

Akshatha Kotian and Vijaya Kumar Deekshit Anirban chakraborty have conceptualised the study, Akshatha Kotian,Vankadari Aditya, Jassiya Sheikh and Sreya Saikrishnan have contributed to the experimental design and execution. Anirban Chakraborty, Praveen Rai and Indrani Karunasagar have contributed to the data revision.

\section{References}

1. Brunette GW. CDC yellow book 2020: health information for international travel. Oxford University Press; 2019. Chapter 3 
2. Brunelle BW, Bearson BL, Bearson SMD (2014) Chloramphenicol and tetracycline decrease motility and increase invasion and attachment gene expression in specific isolates of multidrug-resistant Salmonella enterica serovar typhimurium. Front Microbiol 5:1-12. https://doi.org/10.3389/fmicb.2014.00801

3. Chen HM, Wang Y, Su LH, Chiu CH (2013) Nontyphoid Salmonella infection: Microbiology, clinical features, and antimicrobial therapy. Pediatr Neonatol 54:147-152. https://doi.org/10.1016/j.pedneo.2013.01.010

4. Clements M, Eriksson S, Tezcan-Merdol D, Hinton JC, Rhen M (2001) Virulence gene regulation in Salmonella enterica. Ann Med 33:178-185 https://doi.org/10.3109/07853890109002075

5. CLSI. Performance Standards for Antimicrobial Susceptibility Testing. 28th ed. CLSI supplement M100. Wayne, PA: Clinical and Laboratory Standards Institute; 2018.

6. Deekshit VK, Kumar BK, Rai P, Srikumar S, Karunasagar I, Karunasagar I (2012) Detection of class 1 integrons in Salmonella Weltevreden and silent antibiotic resistance genes in some seafoodassociated nontyphoidal isolates of Salmonella in south-west coast of India. J Appl Microbiol 112:1113-1122. https://doi.org/10.1111/j.1365-2672.2012.05290.x

7. Deekshit VK, Kumar BK, Rai P, Karunasagar I, Karunasagar I (2015) Differential expression of virulence genes and role of gyrA mutations in quinolone resistant and susceptible strains of Salmonella Weltevreden and Newport isolated from seafood. J Appl Microbiol 119:970-980. https://doi.org/10.1111/jam.12924

8. Dichtl S, Demetz E, Haschka D, Tymoszuk P, Petzer V, Nairz M, Seifert M, Hoffmann A, Brigo N, Würzner R, Theurl I (2019) Dopamine Is a Siderophore-Like Iron Chelator That Promotes Salmonella enterica Serovar Typhimurium Virulence in Mice. MBio 10:1-13.

https://doi.org/10.1128/mBio.02624-18

9. Ferric C. Fang1 2, Frawley2 ER, , Timothy Tapscot (2014) Bacterial Stress Responses during Host Infection. Physiol Behav 63:1-18. https://doi.org/10.1016/j.chom.2016.07.009 Foster JW (1995) How Salmonella Survive Against the Odds. Annu Rev Microbiol 49:145-174. https://doi.org/10.1146/annurev.micro.49.1.145

10. Gonzales-Siles L, Sjöling $\AA$ (2016) The different ecological niches of enterotoxigenic Escherichia coli. Environ Microbiol 18:741-751. https://doi.org/10.1111/1462-2920.13106

11. Gunasekera TS, Csonka LN, Paliy O (2008) Genome-wide transcriptional responses of Escherichia coli K-12 to continuous osmotic and heat stresses. J Bacteriol 190:3712-3720. https://doi.org/10.1128/JB.01990-07

12. Hong $\mathrm{H}$, Jung J, Park W (2014) Plasmid-encoded tetracycline efflux pump protein alters bacterial stress responses and ecological fitness of acinetobacter oleivorans. PLoS One. https://doi.org/10.1371/journal.pone.0107716

13. Jorgensen JH, Ferraro MJ (2009) Antimicrobial Susceptibility Testing: A Review of General Principles and Contemporary Practices. Clin Infect Dis 49:1749-1755. https://doi.org/10.1086/647952 
14. Kortman GAM, Boleij A, Swinkels DW, Tjalsma H (2012) Iron availability increases the pathogenic potential of Salmonella typhimurium and other enteric pathogens at the intestinal epithelial interface. PLoS One 7:1-7. https://doi.org/10.1371/journal.pone.0029968

15. Kotian A, Aditya V, Jazeela K, Karunasagar I, Karunasagar I, Deekshit VK (2020) Effect of bile on growth and biofilm formation of non-typhoidal Salmonella serovars isolated from seafood and poultry. Res Microbiol 171:165-173. https://doi.org/10.1016/j.resmic.2020.06.002

16. Livak KJ, Schmittgen TD (2001) Analysis of relative gene expression data using real-time quantitative PCR and the 2- $\triangle \triangle C T$ method. Methods 25:402-408. https://doi.org/10.1006/meth.2001.1262

17. Majowicz SE, Musto J, Scallan E, Angulo FJ, Kirk M, O'Brien SJ, Jones TF, Fazil A, Hoekstra RM, (2010) The Global Burden of Nontyphoidal Salmonella Gastroenteritis . Clin Infect Dis 50:882-889. https://doi.org/10.1086/650733

18. Schwarz S, Kehrenberg C, Doublet B, Cloeckaert A (2004) Molecular basis of bacterial resistance to chloramphenicol and florfenicol. FEMS Microbiol Rev 28:519-542. https://doi.org/10.1016/j.femsre.2004.04.001

19. Spector MP, Kenyon WJ (2012) Resistance and survival strategies of Salmonella enterica to environmental stresses. Food Res Int 45:455-481. https://doi.org/10.1016/j.foodres.2011.06.056

20. Theophel K, Schacht VJ, Schlüter M, Schnell S, Stingu CS, Schaumann R, Bunge M (2014) The importance of growth kinetic analysis in determining bacterial susceptibility against antibiotics and silver nanoparticles. Front Microbiol 5:1-10. https://doi.org/10.3389/fmicb.2014.00544

21. Winfield MD, Groisman E (2003) Role of Nonhost Environments in the Lifestyles of. Appl enviromental Microbiol 69:3687-3694. https://doi.org/10.1128/AEM.69.7.3687

22. Yoon H, Park BY, Oh MH, Choi KH, Yoon Y (2013) Effect of $\mathrm{NaCl}$ on heat resistance, antibiotic susceptibility, and Caco-2 cell invasion of Salmonella. Biomed Res Int 2013:1-6. https://doi.org/10.1155/2013/274096

\section{Tables}

\section{Table 1}

\section{Oligonucleotides used in the study}




\begin{tabular}{|c|c|c|c|c|}
\hline Gene & Primer sequence 5'à3' & $\begin{array}{l}\text { Annealing } \\
\text { temperature } \mathbb{} \text { C }\end{array}$ & $\begin{array}{l}\text { Product } \\
\text { size (bp) }\end{array}$ & Reference \\
\hline \multirow[t]{2}{*}{$\operatorname{inv} A$} & $\begin{array}{l}\text { F- } \\
\text { GTGAAATTATCGCCACGTTCGGGCAA }\end{array}$ & \multirow[t]{2}{*}{54} & \multirow[t]{2}{*}{284} & \multirow[t]{2}{*}{$\begin{array}{l}\text { Rahn et al., } \\
1992\end{array}$} \\
\hline & R- TCATCGCACCGTCAAAGGAACC & & & \\
\hline \multirow[t]{2}{*}{ hilc } & F-CAGCCGAACAAATTTCCATT & \multirow[t]{2}{*}{54} & \multirow[t]{2}{*}{204} & \multirow[t]{2}{*}{ This study } \\
\hline & R-ATGCCCTTCTATTTCGCTCA & & & \\
\hline \multirow[t]{2}{*}{ sseA } & F-CTTGCTGAAAGGGCAGAGAG & \multirow[t]{2}{*}{54} & \multirow[t]{2}{*}{176} & \multirow[t]{2}{*}{ This study } \\
\hline & R-GGGGCTTGAGCATTAAGTTG & & & \\
\hline \multirow[t]{2}{*}{$s s r B$} & F-AATGCCTGTTGTGCATACGA & \multirow[t]{2}{*}{54} & \multirow[t]{2}{*}{176} & \multirow[t]{2}{*}{ This study } \\
\hline & R-TTAGCACCTGCGGCTAAAGT & & & \\
\hline \multirow[t]{2}{*}{ flic2 } & F-CCAGGTCAGAACGTAACGTGTCAA & \multirow[t]{2}{*}{54} & \multirow[t]{2}{*}{133} & \multirow{2}{*}{$\begin{array}{l}\text { Cummings et } \\
\text { al., } 2006\end{array}$} \\
\hline & R-GCAAGTAAAGCCGAAGGTCACAAC & & & \\
\hline \multirow[t]{2}{*}{$i c d A$} & F-TGGTATCGGTGTTGATGTCACTC & \multirow[t]{2}{*}{54} & \multirow[t]{2}{*}{140} & \multirow{2}{*}{$\begin{array}{l}\text { Paiva et al., } \\
2009\end{array}$} \\
\hline & R-CATCCTGGCCGTAAACCTGTGTG & & & \\
\hline
\end{tabular}

Table 2a

MIC Variation under control condition and on antibiotic exposure for SW9. Antibiotic shock was given for a duration of $30 \mathrm{~min}$ after growing the isolate to MEP. 


\begin{tabular}{|c|c|c|c|c|c|c|c|}
\hline \multirow{3}{*}{$\begin{array}{l}\text { Antibiotic } \\
(\mu \mathrm{g} / \mathrm{ml})\end{array}$} & \multirow{3}{*}{$\begin{array}{l}\text { LB } \\
\text { broth } \\
\text { Control }\end{array}$} & \multicolumn{2}{|l|}{ Salt } & \multicolumn{2}{|c|}{ High Iron } & \multicolumn{2}{|l|}{ Low Iron } \\
\hline & & & $0.3 \mathrm{M} \mathrm{NaCl}$ & & $\mathrm{FeCl}_{3}+$ & & 2,2- \\
\hline & & $\begin{array}{l}0.3 \mathrm{M} \\
\mathrm{NaCl}\end{array}$ & $\begin{array}{l}\text { + Antibiotic } \\
\text { shock }\end{array}$ & $\mathrm{FeCl}_{3}$ & $\begin{array}{l}\text { Antibiotic } \\
\text { shock }\end{array}$ & $\begin{array}{l}\text { 2,2- } \\
\text { Dipyridyl }\end{array}$ & $\begin{array}{l}+ \\
\text { Antibiotic } \\
\text { shock }\end{array}$ \\
\hline Tetracycline & $>256$ & 3 & 2 & 48 & 48 & 32 & 24 \\
\hline Nalidixic Acid & $>256$ & 1.5 & 0.75 & 24 & 16 & 12 & 6 \\
\hline Chloramphenicol & $>256$ & 2 & 1 & 48 & 24 & 16 & 8 \\
\hline Co-trimoxazole & $>32$ & 0.047 & 0.012 & 0.023 & 0.016 & 0.032 & 0.012 \\
\hline
\end{tabular}

\section{Table 2b}

MIC Variation under control condition and on antibiotic exposure for SN36. Antibiotic shock was given for a duration of $30 \mathrm{~min}$ after growing the isolate to MEP. 


\begin{tabular}{|c|c|c|c|c|c|c|c|}
\hline \multirow{3}{*}{$\begin{array}{l}\text { Antibiotic } \\
(\mu \mathrm{g} / \mathrm{ml})\end{array}$} & \multirow{3}{*}{$\begin{array}{l}\text { LB } \\
\text { broth } \\
\text { Control }\end{array}$} & \multicolumn{2}{|l|}{ Salt } & \multicolumn{2}{|c|}{ High Iron } & \multicolumn{2}{|l|}{ Low Iron } \\
\hline & & & $0.3 \mathrm{M} \mathrm{NaCl}$ & & $\mathrm{FeCl}_{3}+$ & & 2,2- \\
\hline & & $\begin{array}{l}0.3 \mathrm{M} \\
\mathrm{NaCl}\end{array}$ & $\begin{array}{l}\text { + Antibiotic } \\
\text { shock }\end{array}$ & $\mathrm{FeCl}_{3}$ & $\begin{array}{l}\text { Antibiotic } \\
\text { shock }\end{array}$ & $\begin{array}{l}\text { 2,2- } \\
\text { Dipyridyl }\end{array}$ & $\begin{array}{l}+ \\
\text { Antibiotic } \\
\text { shock }\end{array}$ \\
\hline Ampicillin & $>256$ & 1 & 0.50 & 1 & 0.75 & 1.5 & 1 \\
\hline Tetracycline & 24 & 1.5 & 1 & 1.5 & 1.5 & 8 & 6 \\
\hline Nalidixic Acid & 32 & 1.5 & 1.5 & 1.5 & 1 & 1.5 & 1.5 \\
\hline Chloramphenicol & 32 & 1.5 & 1.5 & 2 & 1.5 & 3 & 1.5 \\
\hline Co-trimoxazole & $>256$ & 0.012 & 0.012 & 0.016 & 0.012 & 0.016 & 0.016 \\
\hline
\end{tabular}

\section{Figures}
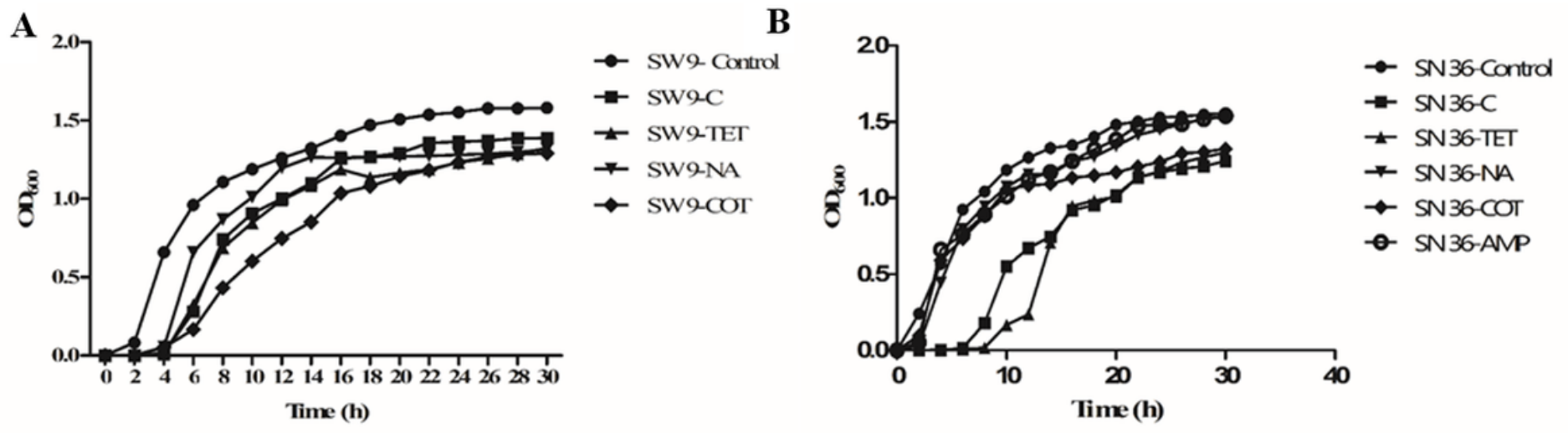

Figure 1

Variations in growth rates between the serovars in the presence of antibiotics Bacterial growth kinetics observed in MDR serovars (A) - SW9 and (B)- SN36 in LB broth supplemented with different class of antibiotics and antibiotic free media as control. C-Chloramphenicol $(\geq 32 \mu \mathrm{g} / \mathrm{ml})$; TET- 
Tetracycline $(\geq 16 \mu \mathrm{g} / \mathrm{ml})$; NA- Nalidixic acid $(\geq 32 \mu \mathrm{g} / \mathrm{ml})$; COT- Co-trimoxazole $(\geq 4 / 76 \mu \mathrm{g} / \mathrm{ml})$ and LB broth devoid of antibiotics as control.
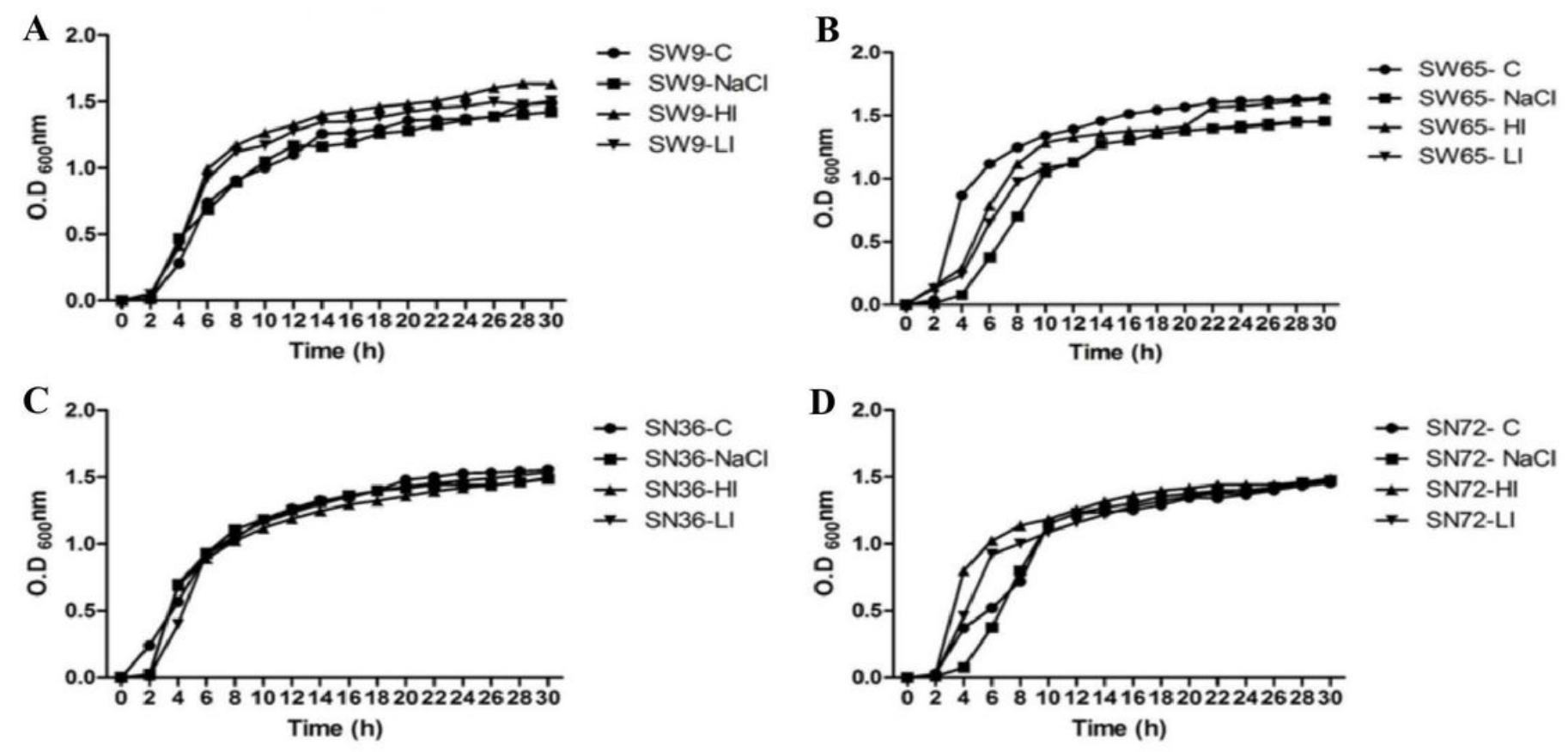

Figure 2

Effect of $\mathrm{NaCl}$, high iron and low iron condition on growth kinetics of MRD and MDS serovars Bacterial growth kinetics observed in MDR serovars (A) SW9 and (C) SN36 and MDS serovars (B) SW65 and SN72 (D) in LB media supplemented with salt ( $\mathrm{NaCl})-0.3 \mathrm{M} \mathrm{NaCl}$, High iron (HI)- $\mathrm{FeCl} 3$, Low iron (LI)- 2,2dipyridyl and LB broth devoid of supplements as Control (C). 

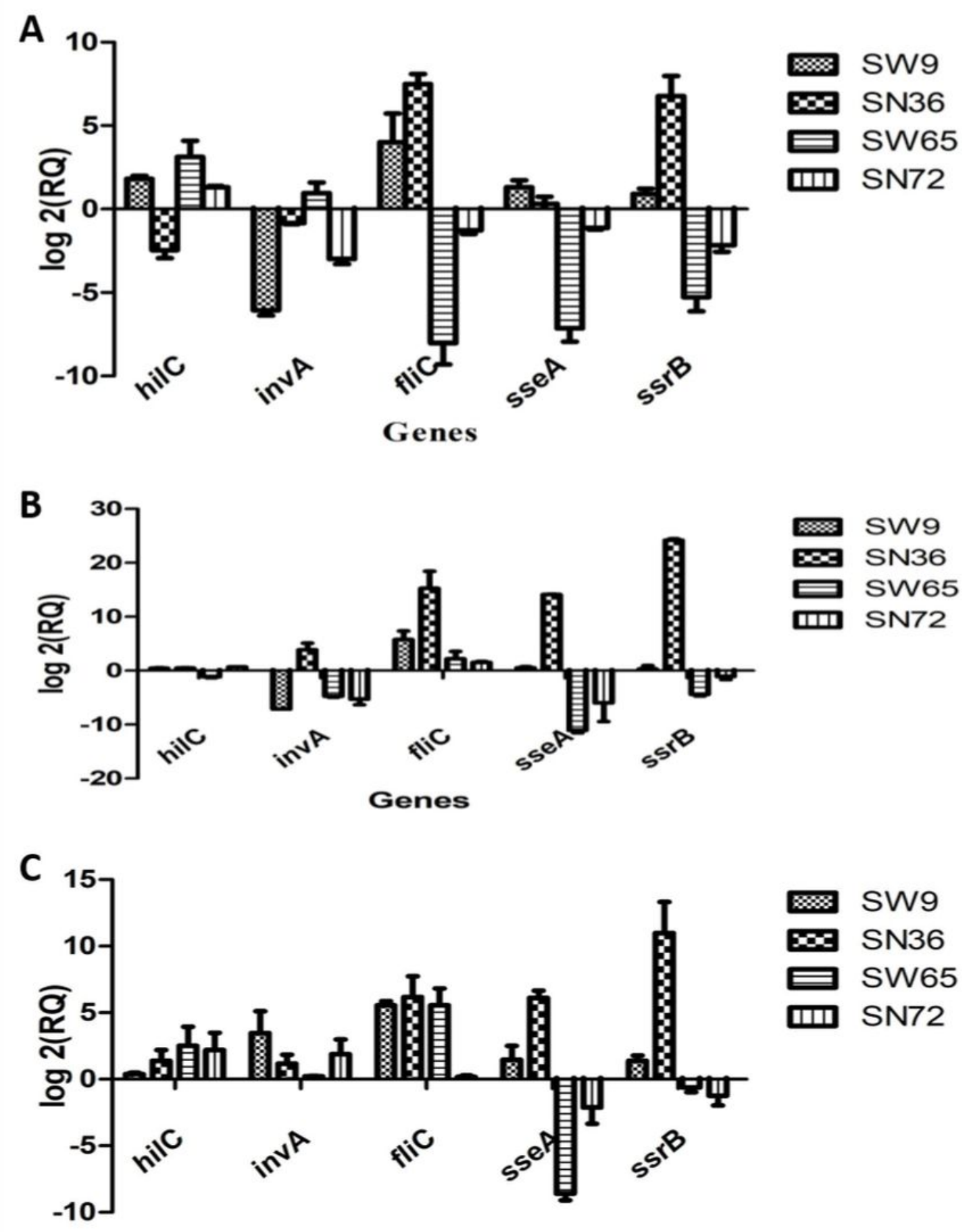

Genes

Figure 3

Variation in differential gene expression of MDR serovars (SW9 and SN36) and MDS serovars (SW65 and SN72) on exposure to (A) 0.3M NaCl; (B) High iron - FeCl3; (C)- Low iron -2,2-dipyridyl. 

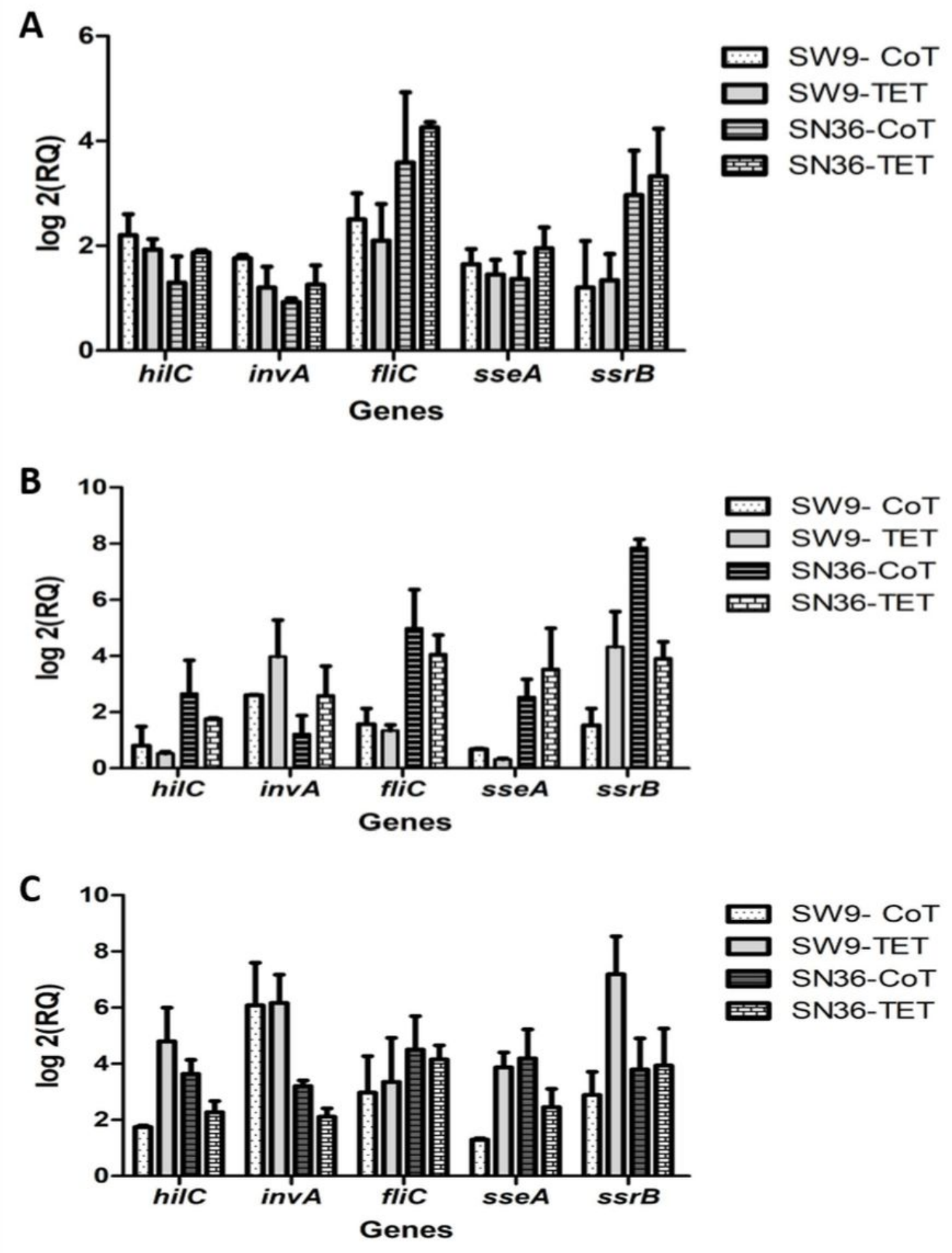

Figure 4

Variation in differential gene expression of MDR serovars (SW9 and SN36) on exposure to tetracycline and Co-trimoxazole. (A) 0.3M NaCl + Antibiotics (B) High iron + antibiotic FeCl3; (C)- Low iron - 2,2dipyridyl + Antibiotics. 